\title{
Article \\ Preparation of Novel Crosslinking Type Resins Based on Calix[4]arene Tetracarboxylate with High Selectivity and High Loading Capacity for Lead Ion
}

\author{
Keisuke OHTO, Tomomi YAMASAKI, Shin-ya WAKISAKA, Takaaki SHINOHARA and Katsutoshi INOUE \\ Department of Applied Chemistry, Faculty of Science and Engineering, Saga University, 1-Honjo, Saga 840-8502, \\ Japan
}

(Manuscript submitted January 29, 2003; accepted May 16, 2003)

\begin{abstract}
Novel resins have been prepared by crosslinking calix[4]arene tetracarboxylate units each other by methylene groups to investigate their solubility to some organic solvents and basic solutions, and their adsorption behavior for lead(II), zinc(II), copper(II), nickel(II), and cobalt(II). The present resins exhibit high selectivity to lead due to the special complexation nature of calix[4]arene tetracarboxylate. The sequence of adsorptive selectivity for metal ions is as follows: $\mathrm{Pb}$ (II) » $\mathrm{Cu}$ (II) $>\mathrm{Zn}$ (II) $\approx \mathrm{Co}$ (II) $\approx \mathrm{Ni}$ (II). The resin prepared by crosslinking calix[4]arene units using trioxane as the crosslinking reagent with the molar ratio $1: 1$ (calix[4]arene unit:trioxane) exhibit the highest loading capacity for lead ion, $2.10 \mathrm{~mol} \mathrm{~kg}^{-1}$.
\end{abstract}

\section{Introduction}

Calixarenes, phenolic cyclic oligomers, are still attractive and interesting host compounds.[1,2] Calixarene derivatives exhibit peculiar complexation behavior. A number of studies on ionic recognition have been conducted. We have also been attracted to their ionic recognition property and have employed them not only as solvent extraction reagents, but also as ion exchange resins for practical use in recent years.[3-5] We have prepared three types of ion exchange resins including calixarene moieties. The first is chemically supported onto polyallylamine, the second is that the solvent extraction reagents are incorporated into macroporous polymer matrix. The third is the resin in which the calixarene is crosslinked each other by a crosslinking reagent.

Compared with another two resins, the crosslinked type resin has many advantages, such as chemical stability, easy preparation, and high loading capacity of metal ions. From the comparison of three resins, the loading capacity is related to the content of calixarene moiety in the resin. It means not only that the crosslinking type resin contains higher content of calixarene than the supported and the impregnated resins, but also that we would prepare more excellent resin with higher loading capacity, if we can increase the calixarene content in the resin.

In the present paper, we report on crosslinking type resins based on calix[4]arene with higher loading capacity to divalent metal ions. Solubility of the resins to some organic solvents and inorganic solutions was examined. Adsorption of divalent ions on the resins was investigated. 


\section{Experimental}

2.1 Materials

The resin was prepared by means of condensation of $25,26,27,28$ tetrakis(carboxymethoxy)calix[4]arene in cone conformation (abbreviated as [4] $\mathrm{CH}_{2} \mathrm{COOH}$ ) using s-trioxane as crosslinking reagent in the presence of acetic acid together with sulfuric acid as a catalyst as described in the previous paper.[6] In the present work, the reaction ratio of $[4] \mathrm{CH}_{2} \mathrm{COOH}$ to trioxane was changed from $1: 5$ to $1: 1(\mathrm{~mol} / \mathrm{mol})$. The resin prepared by the ratio $1: 5\left([4] \mathrm{CH}_{2} \mathrm{COOH}\right.$ to trioxane) is abbreviated as Resin 1, the 1:3 and 1:1 resins are also abbreviated as Resin 2 and 3,

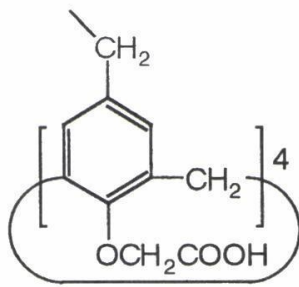

Fig.1 Ideal structure of the resin respectively. The ideal structure of the resins is shown in Fig.1. The forms of the resin and the starting compound are observed by SEM.

\subsection{Solubility of the resin}

A certain amounts of the starting material or resins were taken to the vial and organic solvent or basic solution was added to the resin. The mixture was settle for a night. The solubility degree was simply judged by our eyes.

\subsection{Metal adsorption Procedures}

The batchwise adsorption experiments were carried out by the conventional method.[3-6] Aqueous metal solutions $\left(0.1 \mathrm{mmol} \mathrm{\textrm {dm } ^ { - 3 }}\right)$ were prepared by dissolving individual metal chlorides into $0.1 \mathrm{~mol} \mathrm{dm}^{-3}$ hydrochloric acid and $0.1 \mathrm{~mol} \mathrm{dm}^{-3}$ HEPES buffer solutions, followed by arbitrarily mixing these solutions to adjust $\mathrm{pH}$. The resin $(0.02 \mathrm{~g})$ was added to $10 \mathrm{~cm}^{3}$ of the solution, and the mixture was stirred at $303 \mathrm{~K}$ to equilibration. After the filtration, the metal concentration and $\mathrm{pH}$ of the aqueous solution were measured by atomic absorption spectrophotometer (Perkin Elmer, AAnalyst 100, abbreviated as AAS) and a pH meter (Beckman, $\phi 45)$, respectively.

\section{Results and Discussion}

\subsection{Form of the resin}

The SEM picture of the resin is shown

in Fig.2, together with that of the starting material, [4] $\mathrm{CH}_{2} \mathrm{COOH}$. The starting material [4] $\mathrm{CH}_{2} \mathrm{COOH}$ is apparently squama crystal form. The resin, however, changed to amorphous form. Although the crosslinking degree (i.e. molecular weight) has not been measured, the single molecule was found to be changed to polymer
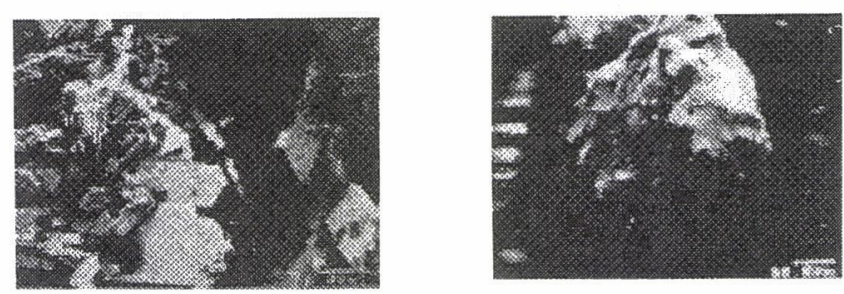

Fig.2 SEM photos of [4]CH2 $\mathrm{COOH}$ (left) and the resin one.

\subsection{Solubility of the resin}

The solubility test was simply judged by our eyes. Solubility test of the resin in various media is listed in Table 1. Before the polymerization, $[4] \mathrm{CH}_{2} \mathrm{COOH}$ was soluble not to only basic aqueous solutions, but also to some organic solvents, whereas the resins are insoluble to any organic solvents. From the comparison of the solubility for the resins, Resin 1 with high crosslinking was found to be less soluble in basic solutions to Resins 2 and 3 with low crosslinking degree. Therefore, solubility to organic solvents are suppressed with the crosslinking and the crosslinking degree is related to the solubility to basic solution. 


\subsection{Batchwise Ion exchange property}

Effect of equilibrium $\mathrm{pH}$ on the percentage adsorption of divalent metal ions on the Resin 3 is shown in Fig.3, as a typical result. The selectivity sequence of the divalent metal adsorption is $\mathrm{Pb} » \mathrm{Cu}>\mathrm{Zn} \approx \mathrm{Co} \approx \mathrm{Ni}$. This order is in good agreement with that observed in the solvent extraction by using p-tert-octylcalix[4]arene carboxylate.[7] It is also similar to those observed in the adsorption by using the supported-type[3,5] and the impregnated-type[4] resins. Comparing the present resins with the commercial ion-exchange resin, the order is the same, while the selectivity to lead(II) of the present resins is much higher than that of the commercial ion-exchange resin. Therefore, the selectivity is attributed not only to high affinity of metal ion with the carboxylate functional group, but also to the special structural effect of calixarene.[3] The Resin 1 and 2 show similar metal selectivity and adsorption efficiency. In order to increase the calix[4]arene content, the ratio of calix[4]arene to $s$-trioxane was changed in preparing the resins. However, adsorptive $\mathrm{pH}$ regions of metal ions for each resin were almost the same and significant difference was not observed in the $\mathrm{pH}$ dependency on the adsorption among these resins.

Adsorption isotherms of lead (II) ion on the present resins are shown in Fig.4. where amount of adsorption, $q\left(\mathrm{~mol} \mathrm{~kg}^{-1}\right)$, is calculated by eq.(1);

$$
q=\frac{C_{i}-C_{e}}{w} \times V
$$

where $C_{i}$ and $C_{e}\left(\mathrm{~mol} \mathrm{dm}^{-3}\right)$ are initial and equilibrium concentrations of metal ions in aqueous solution, respectively; $w(\mathrm{~kg})$ and $V\left(\mathrm{dm}^{3}\right)$ are weight of the resin and volume of aqueous solution, respectively. For the present resins, the amounts of adsorbed lead increase with the increase in lead concentration and approach constant values corresponding to the maximum loading capacities of lead ion, which was evaluated as $1.32,1.67$,
Table 1 Solubility test of the resin in various media.

\begin{tabular}{ccccc} 
& {$[4] \mathrm{CH}_{2} \mathrm{COOH}$} & Resin 1 & Resin 2 & Resin 3 \\
$0.05 \mathrm{M} \mathrm{NaOH}$ & $\mathrm{O}$ & $\times$ & $\mathrm{O}$ & $\bigcirc$ \\
$0.1 \mathrm{M} \mathrm{NaOH}$ & $\mathrm{O}$ & $\mathrm{O}$ & $\mathrm{O}$ & $\bigcirc$ \\
$0.1 \mathrm{M} \mathrm{HNO}_{3}$ & $\times$ & $\times$ & $\times$ & $\times$ \\
$0.1 \mathrm{M} \mathrm{HCl}$ & $\times$ & $\times$ & $\times$ & $\times$ \\
$0.1 \mathrm{M} \mathrm{NH}_{4} \mathrm{OH}$ & $\times$ & $\times$ & $\mathrm{O}$ & $\bigcirc$ \\
$\mathrm{H}_{2} \mathrm{O}$ & $\times$ & $\times$ & $\times$ & $\times$ \\
$\mathrm{Chloroform}_{\text {Methanol }}$ & $\mathrm{O}$ & $\times$ & $\times$ & $\times$ \\
Ethanol & $\times$ & $\times$ & $\times$ & $\times$ \\
DMSO & $\times$ & $\times$ & $\times$ & $\times$ \\
Acetone & $\mathrm{O}$ & $\times$ & $\times$ & $\times$ \\
\hline
\end{tabular}

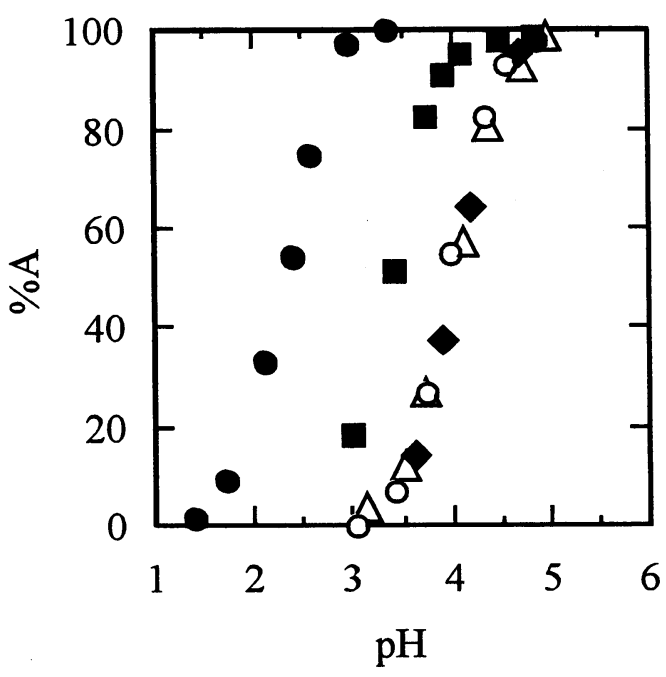

Fig. 3 Effect of $\mathrm{pH}$ on \% adsorption on Resin 3.

○: $\mathrm{Pb}(\mathrm{II}), \mathbf{\square}: \mathrm{Cu}(\mathrm{II}), \mathrm{O}: \mathrm{Zn}(\mathrm{II}), \diamond: \mathrm{Ni}(\mathrm{II})$, $\Delta: \operatorname{Co}(\mathrm{II})$

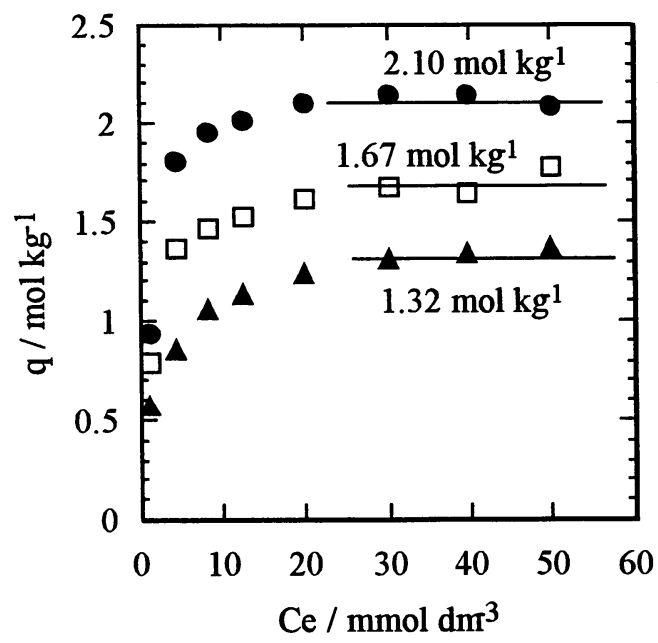

Fig.4 Adsorption isotherm of lead (II) ion on the resins. $\boldsymbol{A}$ : Resin 1, $\square$ : Resin 2, O: Resin 3 
and $2.10 \mathrm{~mol} \mathrm{~kg}^{-1}$ for Resin 1,2, and 3, respectively. These values are much higher compared with those of the supported-type resin $\left.(0.62 \mathrm{~mol} \mathrm{~kg})^{-1}\right)[4]$ and the impregnated-type resin $\left(0.30 \mathrm{~mol} \mathrm{~kg}^{-1}\right)$.[3] Furthermore, the maximum loading capacity of lead ion on carboxylate type of the commercial ion-exchange resin was evaluated as $1.89 \mathrm{~mol} \mathrm{~kg}^{-1}$ by Langmuir plot. The maximum loading capacity for Resin 3 is comparable or rather higher than that of the commercial ion-exchange resin. The content of calix[4]arene in the resin is not drastically changed by changing the ratio of $[4] \mathrm{CH}_{2} \mathrm{COOH}$ to trioxane; i.e. they are $1.3,1.5$, and $1.5 \mathrm{~mol} \mathrm{~kg}^{-1}$ for Resin 1,2 , and 3 , respectively. The maximum loading capacity for Resins 2 and 3 is obviously higher than the content of calix[4]arene. In our previous work on the solvent extraction of lead ion with $p$-tert-octylcalix[4]arene tetracarboxylate, we reported that the stoichiometry of lead and the extractant is 2:1.[7] The peculiar stoichiometry between calix[4]arene tetracarboxylate and lead(II) was also observed. The stoichiometry of lead and calix[4] arene component is varied from $1: 1$ to $2: 1$ by changing the ratio of $[4] \mathrm{CH}_{2} \mathrm{COOH}$ to trioxane from $1: 5$ up to $1: 1$. When the ratio of $[4] \mathrm{CH}_{2} \mathrm{COOH}$ to trioxane is $1: 5$, the degree of crosslinking would be too high, which makes the functional groups of calix[4]arene more rigid. It does not take the suitable steric conformation for the adsorption of lead ion. On the contrary, the calix[4]arene fraction is flexibly mobile in the resin consisting of $[4] \mathrm{CH}_{2} \mathrm{COOH}$ and trioxane at the ratio $1: 1$. That is, highly flexible functional groups of calix[4]arene would behave as it is like a single molecule of the extractant. This is considered to be the reason why the stoichiometry of lead and calix[4]arene moiety approach to $2: 1$ and consequently why Resin 3 shows such a high loading capacity to lead.

\section{Acknowledgement}

This work was partly financed by a Grant-in-Aid for Scientific Research No.12750680 from the Ministry of Education, Science and Culture of Japan.

\section{References}

1)C.D.Gutsche, Ed. "Calixarenes Revisited," Royal Society of Chemistry: Cambridge, 1998.

2)Z.Asfari, V.Boehmer, J.M.Harrowfield, J.Vicens, Eds., "Calixarenes 2001", Kluwer Academic Publishers, Netherlands, 2001.

3) Ohto, K.; Senba, Y.; Eguchi, N.; Shinohara, T.; Inoue, K.; Solv.Extr.Res.Dev.Jpn., 6, 101-112 (1999).

4) Ohto, K.; Tanaka, Y.; Yano, M.; Shinohara, T.; Murakami, E.; Inoue, K.; Solvent Extr.Ion Exch., 19, 725-741 (2001).

5) Ohto, K.; Inoue, S.; Eguchi, N.; Inoue, K.; Sep.Sci.Technol., 37(8), 1943-1958 (2002).

6) T.Shinohara, S.Wakisaka, K.Ohto, K.Inoue, Chem.Lett., 2000, 640-641.

7) Ohto, K.; Fujimoto, Y.; Inoue, K.; Anal.Chim.Acta , 387, 61-69 (1999). 